\title{
Aa. Vv., MLA Convention 2002. Selection of Papers
}

\section{Sergio Poli}

\section{OpenEdition}

\section{Journals}

\section{Edizione digitale}

URL: https://journals.openedition.org/studifrancesi/37537

DOI: 10.4000/studifrancesi.37537

ISSN: 2421-5856

\section{Editore}

Rosenberg \& Sellier

\section{Edizione cartacea}

Data di pubblicazione: 15 décembre 2004

Paginazione: 600-601

ISSN: 0039-2944

\section{Notizia bibliografica digitale}

Sergio Poli, «Aa. VV., MLA Convention 2002. Selection of Papers», Studi Francesi [Online], 144 (XLVIII | III) | 2004, online dal 30 novembre 2015, consultato il 08 mai 2021. URL: http://journals.openedition.org/ studifrancesi/37537 ; DOI: https://doi.org/10.4000/studifrancesi.37537

\section{Questo documento è stato generato automaticamente il 8 mai 2021.}

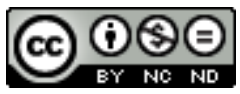

Studi Francesi è distribuita con Licenza Creative Commons Attribuzione - Non commerciale - Non opere derivate 4.0 Internazionale. 


\section{Aa. Vv., MLA Convention 2002. Selection of Papers}

\section{Sergio Poli}

\section{NOTIZIA}

AA. VV., MLA Convention 2002. Selection of Papers, "Papers on French Seventeenth Century Literature", 59, 2003, pp. 347-422.

1 Questo numero si distingue per essere quello del trentennale dei "Papers", e per contenere, tra gli altri contributi e i numerosi, abituali "comptes rendus", una selezione di articoli del convegno della "Modern Language Association", tenutosi a New York alla fine del 2002. Gli atti si aprono con una Nota Editoriale del fondatore dei "Papers", W. Leiner, che ripercorre brevemente le tappe del successo di una rivista che si vuole "tribune vivante d'échanges transatlantiques".

2 La sezione si apre con una Introduction di H. STONE, L. SEIFERT e N. PAGE, in cui viene presentato rapidamente il contenuto dei cinque articoli che la compongono e che si iscrivono in tutto o in parte, malgrado la loro varietà, sotto l'egida non solo della letteratura, ma anche della politica e dell'ideologia. Il primo, per esempio (M. SENIOR, Seeing the Versailles Ménagerie, pp. 351-363) ci mostra la Ménagerie di Versailles, costruita tra il 1662 e il 1664 da Louis Le Vaux, che inaugura un nuovo tipo di zoo: la sua struttura, la sua posizione e la sistemazione degli spazi, però, non solo erano utili a mostrare gli animali che li popolavano, ma costituiscono per noi altrettanti "segni" indicativi della mentalità del tempo. Segni politici, che indicano, con il "contenimento" degli animali più vari in recinti che ne limitavano la reciproca aggressività, il prevalere assoluto del potere del Re anche su esseri di lontane contrade; ideologici, con l'assoluta subordinazione oggettuale delle varietà animali rispetto a uno sguardo umano calante dall'alta torre d'osservazione; estetici, espressi dal trionfo del visivo e della prospettiva, nonché dalle opportunità che la Ménagerie offriva ai "peintres animaliers"; scientifici, 
infine, per il desiderio evidente di repertoriare e di offrire all'analisi specie note e meno note.

3 Per quanto apparentemente lontanissimo, per argomento e per fini, anche il secondo contributo, incentrato sulle versioni seicentesche di un testo ovidiano, ci restituisce il ritratto di una società. L. LEIBACHER-OUVRARD, infatti, nel suo Speculum de l'Autre Femme: les avatars d'Iphis et Ianthé (Ovide) au XVII siècle (pp. 366-377) esaminando le traduzioni della celebre favola ovidiana (Metamorphoses, IX, vv. 666-697) e le opere, sia narrative sia teatrali, che direttamente o indirettamente ad essa si ispirano, affronta nel contempo alcuni temi difficili. Il più scabroso è quello del lesbismo, presente e velato in tanta parte della letterature seicentesca, a partire dal periodo barocco; il secondo è quello del discorso medico-anatomico, che proprio nel Seicento acquista nuove sicurezze; il terzo è quello, ovviamente, del travestitismo che gioca una parte fondamentale nella letteratura del tempo: tutti, però, contribuiscono ad un "discorso" ideologico sul ruolo sociale della donna e su quello della "diversità", un discorso tendente ad affermare sia la subordinazione che l'eterosessualità.

Con Ch. JonEs, Phèdre meets the Transvestite Heroine: Fantastic Variations on Classical Themes (pp. 179-396) siamo ancora nel campo, molto frequentato dalla critica anglosassone, del ruolo femminile in una società maschile, con i temi collegati del potere e del sesso. Nel racconto di Catherine d'Aulnoy, Belle-Belle, ou le chevalier fortuné (1698) confluiscono diverse tradizioni parallele riguardanti la figura, tanto reale quanto funzionale, della donna nel Seicento: quella delle grandi dame della Fronda, ribelli al potere monarchico, ed eredi "al contrario" della mitica Giovanna d'Arco, quella della "femme forte" che le trasporta in letteratura, quella di Fedra, regina raciniana che incarna tragicamente "the disorder associated with human passion and the dangers associated with female rule", quella delle donne travestite, che accendono i compagni - o il Re, come accade per Belle-Belle - ma anche le dame che le circondano, di violente ed equivoche passioni, in cui il gioco dell'amore e quello del potere si mescolano indissolubilmente.

F. ASSAF, invece, inizia a trasportarci dall'interno del "Grand Siècle" all'immagine che ne ebbero i successivi. Qui restiamo ancora ai limiti del regno di Luigi XIV: Il suo Ecriture ou ré-écriture? Les "Apparences trompeuses": comment ne pas s'y tromper? (pp. 397-409), che analizza appunto Les apparences trompeuses, ou les amours du duc de Nemours et de la marquise de Poyanne, attribuito a Courtilz de Sandras, appare infatti nel 1715 ed è probabilmente scritto nel 1709. Un'analisi testuale attenta ed interessante mette in luce il carattere di «pastiche» dell'opera, che può essere letta come «une ré-écriture véritablement antonymique» della Princesse de Clèves, oltre che come un commento particolarmente critico della Francia contemporanea, impoverita da guerre e da crisi economiche e alimentari.

6 Con S. O'HARA, infine, il Seicento di cui si parla è quello visto da E. T .A. Hoffman, in pieno romanticismo tedesco. È un Seicento particolarmente sinistro (E.TA. Hoffmann's sinistre Grand Siècle, pp. 411-419) quello dell'affare dei veleni, descritto dallo scrittore tedesco nel suo Das fraulein von Scuderi: Erzhälung aus dem Zeitatlter Ludwig des Vierzehnten (1820) e sfruttato per creare, raccontando la famosa storia della Marquise de Brinvilliers, una sorta di poliziesco alla Poe ante litteram. Vengono analizzati qui i debiti di Hoff-mann verso le sue fonti (Voltaire e Pitaval) per giungere all'immagine di un Grand Siècle concepito ormai in epoca romantica come eccezionale non soltanto nell'arte e nella letteratura, ma anche nel delitto. 